\title{
Alkaline earth isotope ratios show preservation potential of different carbonate sedimentary components
}

\author{
CLARA BLÄTTLER ${ }^{1}$, ROGER N BRYANT ${ }^{1}$ AND \\ THEODORE PRESENT ${ }^{2}$
}

${ }^{1}$ University of Chicago

${ }^{2}$ California Institute of Technology

Presenting Author: cblattler@uchicago.edu

Marine carbonates offer a rich and nearly continuous geological archive of surface environmental conditions, but their complex sedimentary sources, phases, mineralogies, and diagenesis complicate the interpretation of geochemistry from bulk carbonate rocks. However, this complexity can actually encode additional information: the response of different phases to diagenetic processes can be turned into an advantage to help determine if local or global environmental conditions dominate for a given sample. Isotopic ratios of the major cations in carbonates (calcium and magnesium) can be a useful tool to guide this interpretive approach.

The Permian Reef Complex of the Guadalupe Mountains in west Texas, USA, provides an excellent test case where previously published, multi-dimensional geochemical datasets (including $\mathrm{C}, \mathrm{O}$, and $\mathrm{S}$ isotope ratios) can be used to show how calcium and magnesium isotope ratios respond to a variety of sedimentary and diagenetic processes. This well-studied location has multiple generations of cementation, dolomitization, and recrystallization, and excellent spatial correlations across reef to slope to basinal facies. Magnesium isotope ratios show that dolomitization occurred at high water:rock ratios with no magnesium limitation. Under these conditions, replacement dolomite records properties of seawater chemistry more accurately than other facies that may be closer to their original sedimentology, consistent with interpretations of sulfur, carbon, and oxygen isotope ratios from the Permian Reef Complex [1]. Sedimentary phases preserved as calcite, including several generations of cement, are less faithful recorders of global seawater chemistry, depending on location within the reef complex and the particular isotopic system, but may capture signals of local biogeochemical processes such as sulfate reduction. Across a range of facies, variability in calcium isotope ratios reflects a spectrum of open (advective) versus closed (diffusive) conditions during early marine diagenesis, with corresponding relationships in sulfur and carbon isotope ratios. This work demonstrates the utility of calcium and magnesium isotope ratios for distinguishing the preservation potential of sedimentary carbonates with complex diagenetic histories.

[1] Present, Gutierrez, Paris, Kerans, Grotzinger \& Adkins (2019), Sedimentology 66, 2605-2626. 